\title{
Nucleation/Growth and Optical Proprieties of Co-doped ZnO Electrodeposited on ITO Substrate
}

\author{
Youssef Lghazi ${ }^{1}$, Jihane Bahar ${ }^{1}$, Boubaker Youbi ${ }^{1}$, Mohammed Ait Himi ${ }^{1}$, Chaimaa Elhaimer ${ }^{1}$, \\ Abdessamad Elouadrhiri ${ }^{1}$, Itto Bimaghra ${ }^{1}$, Mohamed Ouknin ${ }^{2}$ (D), Lhou Majidi 2,*(D) \\ 1 Bio-Geosciences and Materials Engineering Laboratory, Higher Normal School, Hassan II University of Casablanca, \\ Casablanca, Morocco \\ 2 Laboratory of Natural Substances Synthesis and Molecular Dynamics, Faculty of Sciences and Techniques, Moulay \\ Ismail University, Errachidia, Morocco \\ * Correspondence: Imajidi@yahoo.fr, lmajidi@fst.umi.ac.ma (L.M.);
}

Scopus Author ID 15760507800

Received: 21.09.2021; Revised: 20.10.2021; Accepted: 23.10.2021; Published: 20.11.2021

\begin{abstract}
A Co-doped ZnO layer was prepared by electrodeposition method on indium doped tin oxide (ITO) substrate using a cathodic reduction from nitrate medium with different doping percentages of cobalt. The bath temperature was controlled at $70{ }^{\circ} \mathrm{C}$. The films were cathodically electrodeposited in a bath containing $5 \mathrm{mM} \mathrm{Zn}\left(\mathrm{NO}_{3}\right)_{2} .6 \mathrm{H}_{2} \mathrm{O}$, while the source of $\mathrm{Co}$ is $\mathrm{Co}\left(\mathrm{NO}_{3}\right)_{2} \cdot 6 \mathrm{H}_{2} \mathrm{O}$ where $0.1 \mathrm{M} \mathrm{KNO}$ was used as supporting electrolyte. The nucleation and growth mechanism of Co-doped $\mathrm{ZnO}$ nuclei have been studied by cyclic voltammetry and chronoamperometry. The cyclic voltammetry shows that the electrodeposition of $\mathrm{ZnO}$ and $\mathrm{Co}$-doped $\mathrm{ZnO}$ at a negative potential around $-1.0 \mathrm{~V}$ versus saturated calomel electrode (SCE) is a quasi-reversible reaction controlled by the diffusion process. Comparing current transients curves obtained by the chronoamperometric method with the theoretical curves of current density $\mathrm{j}$ versus $\mathrm{t} 1 / 2$ allows us to say that the nucleation is $3 \mathrm{D}$ instantaneous, as shown in SEM analysis. The presence of Co does not modify the nucleation and growth mechanism. The XRD patterns show that the substitution of zinc by cobalt does not change the würtzite crystal structure, but the crystallite size decreases with the cobalt percentage. The transmittance spectra indicate that the Codoped $\mathrm{ZnO}$ films are transparent in the visible range. The optical gap increases with the doping percentage of cobalt.
\end{abstract}

Keywords: zinc oxide; Co-doped $\mathrm{ZnO}$ layer; cobalt; electrodeposition; cyclic voltammetry; chronoamperometry; nucleation and growth.

(C) 2021 by the authors. This article is an open-access article distributed under the terms and conditions of the Creative Commons Attribution (CC BY) license (https://creativecommons.org/licenses/by/4.0/).

\section{Introduction}

The development in optoelectronics and spintronics has oriented scientific research towards elaborating dilute magnetic semiconductor materials [1]. In recent years much work has been in accordance with transparent and conductive oxides (TCO) such as $\mathrm{ZnO}$ because of their interesting physical properties, which combine electrical conductivity and optical transparency in the visible spectral range [2]. The substitution of $\mathrm{Zn}^{2+}$ ions in the $\mathrm{ZnO}$ crystal lattice by $\mathrm{Co}^{2+}$ ions, a magnetic element, could improve $\mathrm{ZnO}$ 's optical and magnetic properties [3-5]. Some studies have shown that the Co-doped $\mathrm{ZnO}$ semiconductor is ferromagnetic at room temperature [6-8], and the nucleation and growth mechanism could also influence its properties. The electrodeposition technique of thin films is considered one of the promising ways due to the ability to control the thickness by the transferred charge control, a large area deposition, a simple process, good adhesion, and a low-cost fabrication process [1]. In this 
work, we studied the mechanism of nucleation and growth of the oxides $\mathrm{ZnO}$ and Co-doped $\mathrm{ZnO}$, the structural and optical properties of the thin films of these semiconductors. UV-visible optical spectroscopy, scanning electron microscopy (SEM), and X-ray diffraction (XRD) were used to study electrodeposited layers' optical properties, surface morphologies, and crystal structure.

\section{Materials and Methods}

\subsection{Electrodeposition.}

The $\mathrm{ZnO}$ films were electrodeposited from an aqueous solution containing $0.005 \mathrm{M}$ $\mathrm{Zn}\left(\mathrm{NO}_{3}\right)_{2} .6 \mathrm{H}_{2} \mathrm{O}, 0.1 \mathrm{M} \mathrm{KNO}$ prepared in distilled water. The same electrolytic solution to which $\mathrm{Co}\left(\mathrm{NO}_{3}\right)_{2} .6 \mathrm{H}_{2} \mathrm{O}$ has been added, for percentages of Co from $2 \%$ to $10 \%$, is used to study the co-deposition mechanism of Co-doped $\mathrm{ZnO}$ and the effect of cobalt on the properties of $\mathrm{ZnO}$. The deposition process was performed at $70{ }^{\circ} \mathrm{C}$ in a three-electrode cell with ITO (tin (Sn) doped indium oxide $\left.\left(\operatorname{In}_{2} \mathrm{O}_{3}\right)\right)$ substrate with a surface area of $1 \mathrm{~cm}^{2}$ used as a working electrode, a disc-shaped Glassy carbon electrode $(1.5 \mathrm{~cm}$ in diameter) used as a counter electrode and saturated calomel electrode (SCE) as a reference electrode (all potentials were given versus SCE). Before electrodeposition, the ITO substrate with an exposed area of $1 \mathrm{~cm}$ $\times 1 \mathrm{~cm}$ was first cleaned in acetone and ethanol in an ultrasonic bath for $15 \mathrm{~min}$. Lastly, well rinsed with distilled water. The electrochemical depositions were performed using a VersaStat3 potentiostat/galvanostat assisted by a computer using the versa studio software. The electrodeposition mechanisms were studied by cyclic voltammetry (CV) and Chronoamperometry (CA).

\subsection{Characterization.}

The structure of deposited films was determined by analyzing the X-ray diffraction spectra obtained using the Bruker D8 Advance diffractometer, equipped with a graphite monochromator, a Lynx-Eye detector, and a parallel beam optics using $\mathrm{Cu}$ radiation $\mathrm{K} \alpha(\lambda=$ $1.54184 \AA$ ). In addition, the optical properties of the electrodeposited layers were investigated using a Rayleigh UV-1800 UV/VIS spectrophotometer with a wide wavelength range, and the morphology was carried out by a Philips XL 30FEG scanning electronic microscope (SEM).

\section{Results and Discussion}

\subsection{Cyclic voltammetry}

The electrochemical nucleation and growth processes involved in the initial stages of $\mathrm{ZnO}$ and Co-doped $\mathrm{ZnO}$ electrodeposition on ITO substrate were investigated by cyclic voltammetry and potentiostatic transient measurements. Firstly, cyclic voltammetry is used to define the potential region for deposition and dissolution of $\mathrm{ZnO}$ and $\mathrm{ZnO}$-Co on ITO substrate as well as the reversibility of the system. The cyclic voltammograms in Figure 1, recorded between 0 and $-1.4 \mathrm{Vvs} \mathrm{SCE}$ for a scan rate of $50 \mathrm{mVs}^{-1}$ show the electrochemical behavior during $\mathrm{ZnO}$ and $\mathrm{ZnO}-\mathrm{Co}$ electrodeposition on ITO substrate in the nitrate solution at $70^{\circ} \mathrm{C}$. With these curves is associated a recorded voltammogram for the supporting electrolyte $\left(\mathrm{KNO}_{3}\right)$ alone constituting the blank. 


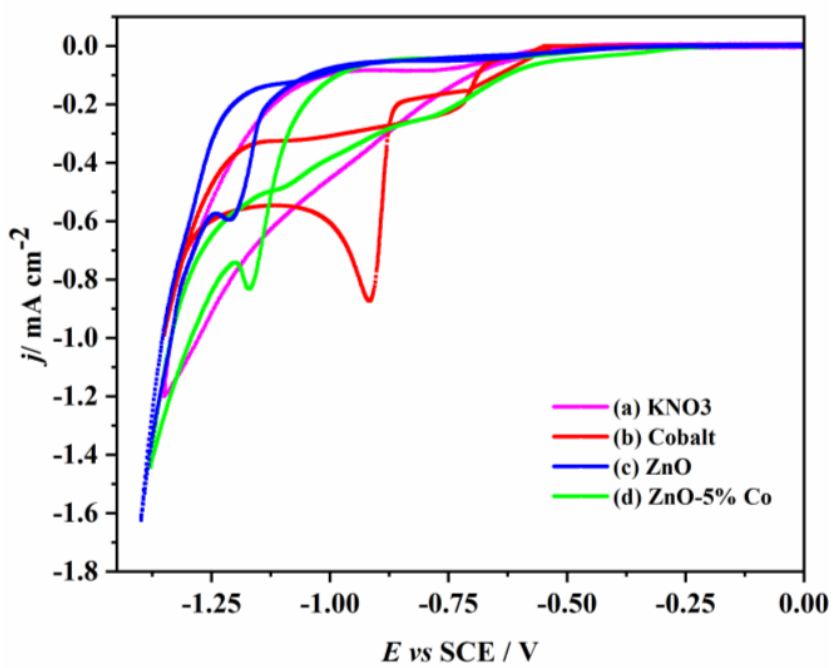

Figure 1. Voltammograms were obtained during the electrodeposition of: (a) $\mathrm{KNO}_{3}$ blank solution; (b) Cobalt; (c) $\mathrm{ZnO}$ alone; (d) $\mathrm{ZnO}-\mathrm{Co}$ at $70{ }^{\circ} \mathrm{C}$.

We note first that the blank voltammogram (curve a) shows the absence of side reactions on the surface of the ITO substrate in nitrate medium, only a peak of reduction of nitrate ions followed by the reduction of hydrogen ions. The curve (c) of $\mathrm{ZnO}$, not doped, shows two peaks of reduction around $-0.85 \mathrm{~V}$ and $-1.15 \mathrm{~V} / \mathrm{SCE}$. The first peak corresponds to the reduction of $\mathrm{Zn}^{2+}$ in metal $\mathrm{Zn}$ according to equation 1 . The second peak could be attributed to the reduction of nitrate ions according to equation 2 . On the return scan, the absence of a $\mathrm{Zn}$ oxidation peak can be explained by the formation of $\mathrm{ZnO}$ during the reduction of the nitrate ion [9]. Some authors have assumed the production of a direct reaction between metallic zinc and nitrate ions [10]. We can say that the deposition of $\mathrm{ZnO}$ occurs according to two parallel mechanisms, the $\mathrm{Zn}^{2+}$ ions are reduced in the first reduction zone and lead to a deposit of metallic $\mathrm{Zn}$ (Eq. 1) which can react chemically with the nitrate ions to give the oxide $\mathrm{ZnO}$ (Eq. 6) [11] in the second reduction zone. The reduction of the negative ion $\mathrm{NO}_{3}$ - into the $\mathrm{NO}_{2}$ - ion near the cathode is catalyzed by metallic $\mathrm{Zn}$ (Eq. 3). During this reduction, the $\mathrm{OH}^{-}$ions are formed, which locally increases the $\mathrm{pH}$ value and leads to the formation of zinc hydroxide $\mathrm{Zn}(\mathrm{OH})_{2}$, which then dehydrates to $\mathrm{ZnO}$. The possible reactions, according to this mechanism, for the formation of the $\mathrm{ZnO}$ film are as follows:

$$
\begin{gathered}
\mathrm{Zn}^{2+}+2 \mathrm{e}^{-} \rightarrow \mathrm{Zn} \\
\mathrm{NO}_{3}^{-}+\mathrm{H}_{2} \mathrm{O}+2 \mathrm{e}^{-} \rightarrow \mathrm{NO}_{2}^{-}+2 \mathrm{OH}^{-} \\
\mathrm{Zn}+\mathrm{NO}_{3}^{-}+\mathrm{H}_{2} \mathrm{O} \rightarrow \mathrm{NO}_{2}^{-}+2 \mathrm{OH}^{-}+\mathrm{Zn}^{2+} \\
\mathrm{Zn}^{2+}+2 \mathrm{OH}^{-} \rightarrow \mathrm{Zn}(\mathrm{OH})_{2} \\
\mathrm{Zn}(\mathrm{OH})_{2} \rightarrow \mathrm{ZnO}+\mathrm{H}_{2} \mathrm{O}
\end{gathered}
$$

The overall mechanism of the reaction between metallic $\mathrm{Zn}$ and nitrate ions can be summarized by the following reaction:

$$
\mathrm{Zn}+\mathrm{NO}_{3}^{-} \rightarrow \mathrm{NO}_{2}^{-}+\mathrm{ZnO}(6)
$$

For more cathodic potentials close to $-1.3 \mathrm{~V} / \mathrm{SCE}$ the reduction potential of nitrate ions is reached. Therefore, the mechanism involved in this region corresponds to that widely accepted in the literature involving the reduction of nitrate ions leading to the precipitation of $\mathrm{ZnO}$ and could take place in parallel with the reaction $(6)[12,13]$. In the curve (b) recorded 
for a solution of $\mathrm{Co}^{2+}$ alone, a cathodic peak close to that of $\mathrm{Zn}$ is also identified. This peak is associated with the deposition of cobalt on ITO substrate, and its location thereof shows the possibility of Co- $\mathrm{ZnO}$ codeposition. Then, the curve (d) of the mixture shows clearly that the presence of cobalt influences the potential of $\mathrm{ZnO}$ and Co deposition and another drop in current density is observed after the $\mathrm{ZnO}$ reduction peak.

Their deposition potentials are approximated to about $200 \mathrm{mV}$ by the shift of the Co deposition peak to the left, which may indicate the formation of a Co-ZnO deposition [14]. The presence of the crossover between the scanning of the potentials towards the cathodic potentials and return towards the anodic potentials give rise to what has been called the "nucleation loop" which indicated the formation of $\mathrm{ZnO}$ and Co-doped $\mathrm{ZnO}$ nucleation on ITO substrate [15]. To deepen this study, different percentages of $\mathrm{Co}^{2+}$ ions were used, as shown in Figure 2, grouping the voltammograms with and without the addition of cobalt.

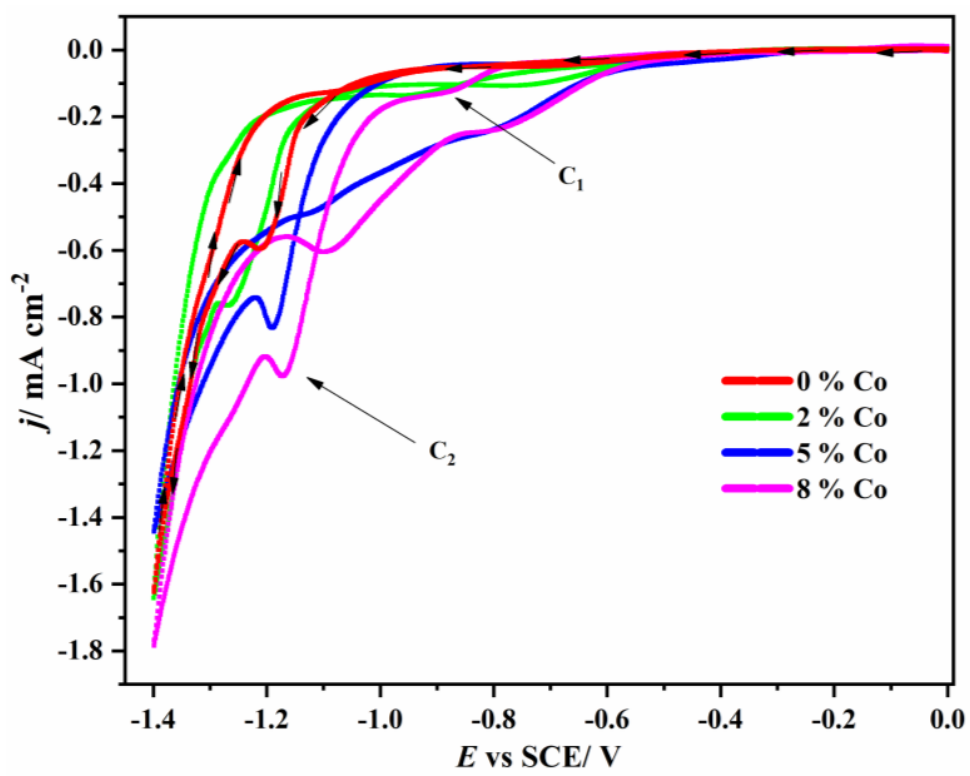

Figure 2. Cyclic voltammograms of different doping Cobalt percentages $(0,2,5$, and $8 \%$ ) with a scan rate of 50 $\mathrm{mVs}^{-1}$ at $70{ }^{\circ} \mathrm{C}$, obtained during the electrodeposition of $\mathrm{ZnO}-\mathrm{Co}$ on ITO substrate.

Figure 2 shows the series of cyclic voltammograms for $\mathrm{ZnO}-\mathrm{Co}$ electrodeposition on ITO substrate at different doping percentages. During the cathodic scan, the voltammograms show the increase of the intensity of the $\mathrm{C}_{1}$ and $\mathrm{C}_{2}$ peaks and its displacement towards the less cathodic potentials with the increase of $\mathrm{Co}^{2+}$ concentration. It is then concluded that other reduction reactions are added to those produced for $\mathrm{ZnO}$ alone. For example, in the first peak, the $\mathrm{Zn}^{2+}$ reduction was accompanied $\mathrm{Co}^{2+}$ reduction (Eq. 7).

$$
\mathrm{Co}^{2+}+2 \mathrm{e}^{-} \rightarrow \text { Co (7) }
$$

According to the same mechanism proposed above for $\mathrm{Zn}$ (Eqs. 2, 3, and 4), under the influence of nitrate ions, the formation of $\mathrm{Co}(\mathrm{OH})_{2}$ and $\mathrm{Zn}(\mathrm{OH})_{2}$ leads to the co-deposition of Co-doped $\mathrm{ZnO}$.

By a reaction similar to that of $\mathrm{Zn}$ (Eq. 3), the influence of nitrate and the increase in the $\mathrm{pH}$ of the medium leads to the formation of $\mathrm{Co}(\mathrm{OH})_{2}$. Then the co-precipitation of $\mathrm{Zn}(\mathrm{OH})_{2}$ and $\mathrm{Co}(\mathrm{OH})_{2}$ form $\mathrm{Zn}_{1-\mathrm{x}} \mathrm{CoxO}$ following the chemical reaction (Eq. 8) [16].

$$
x \mathrm{Co}(\mathrm{OH})_{2}+(1-x) \mathrm{Zn}(\mathrm{OH})_{2} \rightarrow \mathrm{Zn}_{(1-x)} \mathrm{Co}_{x} \mathrm{O}+\mathrm{H}_{2} \mathrm{O} \text { (8) }
$$

During the return sweep, the shape of the voltammograms compared to that of $\mathrm{ZnO}$ alone is in good agreement with the co-electrodeposition of Co- $\mathrm{ZnO}$ [16]. 


\subsection{Chronoamperometry.}

Chronoamperometry is an important electrochemical technique as it provides the current transients, used by Scharifker and Hills, to describe the nucleation process: instantaneous and progressive [17]. The first nucleation type corresponds to the low growth of nuclei on the smaller number of active sites, and all activated simultaneously. The second one corresponds to the fast growth of nuclei on many active sites, all activated during the first stage of electrodeposition. Therefore, the mechanism of nucleation and growth can be determined by analyzing transients current from chronoamperometry measurements [18]. The series of current transient densities for $\mathrm{ZnO}$ and $\mathrm{Co}-\mathrm{ZnO}$ electrodeposition on ITO substrate at different doping percentages $(0,2,5$, and $8 \% \mathrm{Co})$ are shown in Figure 3.

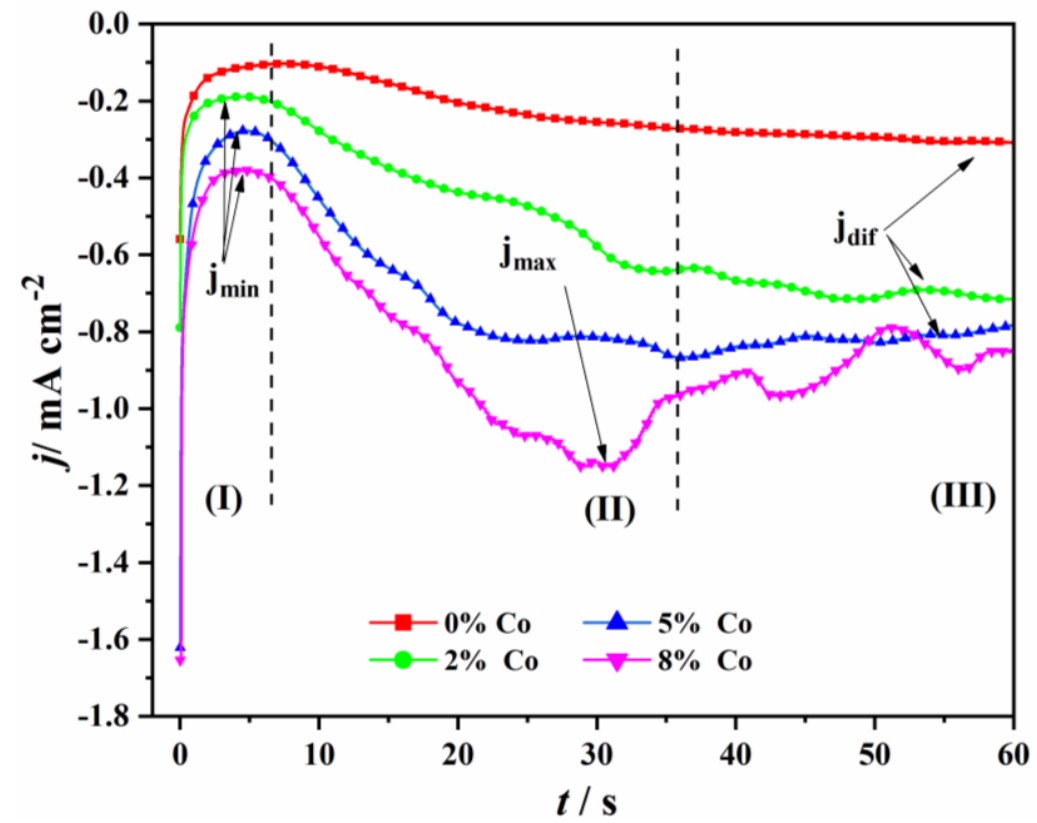

Figure 3. Transients current density for $\mathrm{ZnO}$ and $\mathrm{ZnO}-\mathrm{Co}$ electrodeposition on ITO substrate at different doping percentages, at potential $-1 \mathrm{~V} / \mathrm{SCE}$ and $\mathrm{T}=70^{\circ} \mathrm{C}$.

Figure 3 shows that the current density-time transients obtained have the typical shape of a three-dimensional 3D germination mechanism for $\mathrm{ZnO}$ and $\mathrm{Co}-\mathrm{ZnO}$ electrodeposition on ITO substrate at different doping percentages [19]. We can clearly distinguish three distinct zones (I, II, and III) in these transients for all the percentages in Co.

In the first part (I), we observed that after an initial surge, the current decays abruptly to reach a minimum intensity jmin around $t=5 \mathrm{~s}$. The value of this minimum current density increases with the percentage of $\mathrm{Co}$, which the nucleation can explain in the first reduction steps of cations in the close vicinity of the electrode. Then, in a second step (II), an increase in current is attributed to the growth of germs and the increase in the number of nuclei formed. As the cationic species diffuse towards the substrate, the current gradually increases and reaches the maximum jmax. The current finally stabilizes around a current diffusion jdif in the last part of the transients (III), and the introduction of cobalt ions has the effect of increasing the diffusion current, which is in agreement with the Co- $\mathrm{ZnO}$ codeposition. This behavior shows that a diffusion process controls the $\mathrm{Co}-\mathrm{ZnO}$ electrodeposition, and the weak oscillation observed in the current diffusion jmax may indicate that the co-deposition mechanism of $\mathrm{ZnO}$ Co is multilayered [20]. These features are qualitatively consistent with the model of 3D islands growth under diffusion-limited control. 
3.2.1. Exploitation of the last part (III).

The curve giving the transient current density $\mathrm{j}$ as a function of $\mathrm{t}^{-1 / 2}$ for $(0,2,5$, and $8 \%$ Co) has been plotted as shown in Figure 4. This curve represented a good linear relationship between $(\mathrm{j})$ and $\mathrm{t}^{-1 / 2}$ which is a typical tree-dimensional (3D) multiple nucleations with diffusion-controlled growth according to Cottrell equation (Eq. 9).

$$
j(t)=n F C\left[\frac{D}{\pi t}\right]^{1 / 2}
$$

where $\mathrm{nF}$ is the molar charge transferred during electrodeposition $\left(\mathrm{F}=96500 \mathrm{C}^{\mathrm{mol}}{ }^{-1}\right), \mathrm{C}$ is the bulk concentration of the electroactive species $\left(\mathrm{mol} . \mathrm{L}^{-1}\right), \mathrm{D}$ is the diffusion coefficient $\left(\mathrm{cm}^{2} . \mathrm{s}^{-}\right.$ $\left.{ }^{1}\right)$, and $\mathrm{t}$ is time (s).

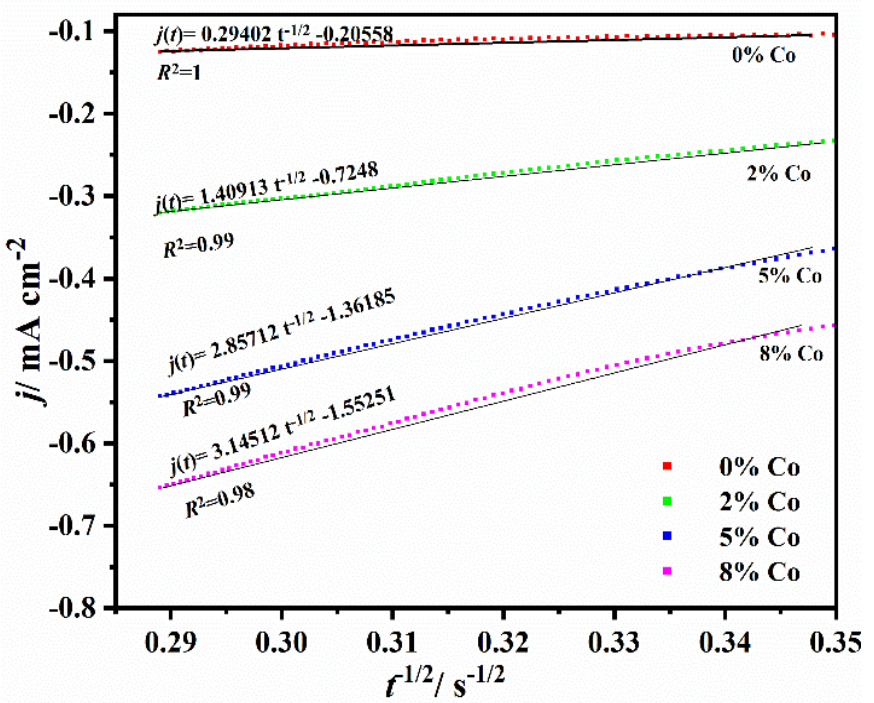

Figure 4. Transients current density (j) versus $\mathrm{t}^{-1 / 2}$ of the last part for different doping rates.

Table 1 shows the diffusion coefficient calculated using the Cottrell equation (Eq. 8) for different doping percentages $(0,2,5$, and $8 \% \mathrm{Co})$ at potential $\mathrm{E}=-1.0 \mathrm{~V} / \mathrm{SCE}$. A slight increase in the diffusion coefficient was observed as the concentration of Co increased. The D average value is about $1.35 \times 10^{-6} \mathrm{~cm}^{2} / \mathrm{s}^{-}$, as reported in the literature [21].

Table 1. Diffusion parameter $\mathrm{D}$ of $\mathrm{ZnO}$ and $\mathrm{ZnO}-\mathrm{Co}$ electrodeposition on ITO substrate at different doping rates.

\begin{tabular}{c|c} 
Doping percentage of Co $(\boldsymbol{\%})$ & $\boldsymbol{D}\left(\times \mathbf{1 0}^{-\mathbf{6}}{\mathbf{~} \mathbf{m}^{\mathbf{2}} \cdot \mathbf{.}}^{-\mathbf{1}}\right)$ \\
\hline 0 & 1.11 \\
\hline 2 & 1.23 \\
\hline 5 & 1.49 \\
\hline 8 & 1.58
\end{tabular}

\subsubsection{Exploitation of the ascending part.}

Scharifker and Hills have developed theoretical models describing the 3D nucleation mechanism for instantaneous and progressive 3D nucleation/growth; the variation of the current density in the second part on the current transients can be described by the following Eqs. 10 and 11 [22]:

For instantaneous 3D nucleation: $j(t)=n F \pi(2 D C)^{\frac{3}{2}}(M / \rho)^{\frac{1}{2}} N_{0} t^{\frac{1}{2}}(10)$

For progressive 3D nucleation: $j(t)=\frac{2}{3} n F \pi(2 D C)^{\frac{3}{2}}(M / \rho)^{\frac{1}{2}} N_{0} A_{N} t^{\frac{3}{2}}$ 
(b) where, $\mathrm{j}(\mathrm{t})$ is the current density $\left(\mathrm{A} . \mathrm{cm}^{-2}\right), \mathrm{C}$ is the concentration of the electroactive ions $\left(\mathrm{mol} . \mathrm{cm}^{-3}\right), \mathrm{D}$ is the diffusion coefficient $\left(\mathrm{cm}^{2} \cdot \mathrm{s}^{-1}\right), \mathrm{F}$ is the faraday constant $\left(96500 \mathrm{C} \cdot \mathrm{mol}^{-1}\right)$, $\mathrm{n}$ is the number of electrons transferred in the electrodeposition process, $\mathrm{M}$ is the molar mass of the deposit $\left(\mathrm{g} \cdot \mathrm{mol}^{-1}\right), \rho$ is the density of the deposit $\left(\mathrm{g} \cdot \mathrm{cm}^{-2}\right), \mathrm{A}$ is the nucleation rate constant $\left(\mathrm{s}^{-1}\right), \mathrm{N}$ is the number density of nuclei $\left(\mathrm{cm}^{-2}\right)$.
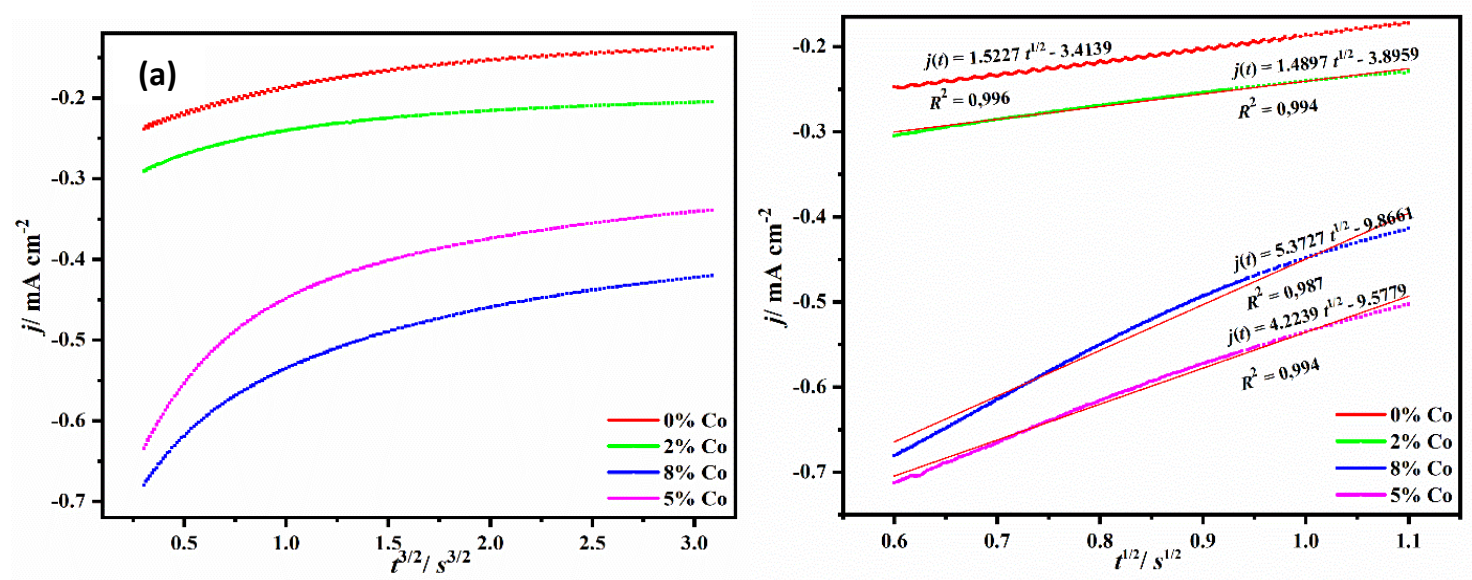

Figure 5. (a) Transients current density (j) versus $\mathrm{t}^{3 / 2}$ of the second part; (b) transients current density (j) versus $\mathrm{t}^{1 / 2}$ of the first part for different doping percentages.

According to equations 10 and 11, for all the transients were presented in Figure 3, the experimental current density of the second part was plotted versus $\mathrm{t}^{1 / 2}$ and $\mathrm{t}^{3 / 2}$ in Figure 5 (a and b). As shown in Figure 5, the plots (j) versus $\mathrm{t}^{1 / 2}$ (Figure 5a) display a good linear relationship for all applied potential with high correlation factors compared to the plots (j) versus $t^{3 / 2}$ (Figure $5 b)$. This implies that the electrochemical deposition of $\mathrm{ZnO}$ and $\mathrm{ZnO}$ doped Co exhibits probably instantaneous 3D nucleation [22, 23].

\section{Characterization}

\subsection{Crystal structure determination.}

The X-ray diffraction patterns of the elaborated sample with electrodeposition method on ITO substrate realized at E= $-1.0 \mathrm{~V} / \mathrm{SCE}$ are shown in Figure 6.

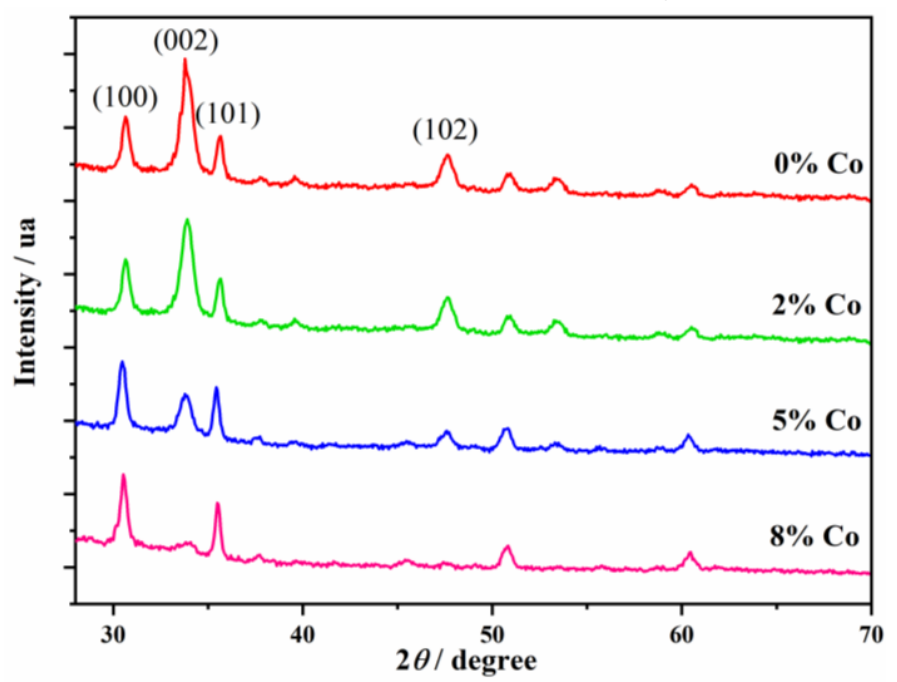

Figure 6. XRD of films deposited on ITO substrate by chronoamperometry: $\mathrm{ZnO}$ and $\mathrm{ZnO}$ doped $\mathrm{Co}$ at (2\% $\mathrm{Co}$, $5 \% \mathrm{Co}$ and $8 \% \mathrm{Co}$ ). 
From the patterns, it is clear that the deposited $\mathrm{ZnO}$ and $\mathrm{Co}$-doped $\mathrm{ZnO}$ thin film is of würtzite type. Figure 6 shows that all peaks from the diffraction patterns at $2 \theta=30.5^{\circ}, 34.5^{\circ}$, $35.5^{\circ}$, and $47.5^{\circ}$ which correspond respectively to planes (100), (002), (101), and (102), are characteristic of $\mathrm{ZnO}$.

In Figure 6, The XRD spectra indicate that the cobalt doping does not change the wurtzite structure of $\mathrm{ZnO}$ and the diffraction peak intensity (002) decreases with the initial Co concentration. Then, the single-phase nature (wurtzite structure) of the XRD patterns of all the doped samples indicates that the Co ion must be successfully incorporated into the $\mathrm{ZnO}$ lattice as a substitutional atom. Moreover, neither peaks corresponding to $\mathrm{CoO}$ and $\mathrm{Co}_{3} \mathrm{O}_{4}$ appear on the spectra indicated, nor moreover secondary crystalline cobalt phase was formed during the electroplating process. The diffraction peaks (002) move to larger diffraction angles as the doping rate increases. This shift is in accordance with the fact that the radius of $\mathrm{Co}^{2+}$ ion $\left(\mathrm{RCo}^{2+}=0.58 \AA\right)$ is slightly smaller than that of $\mathrm{Zn}^{2+}$ cation $\left(\mathrm{RZn}^{2+}=0.60 \AA\right)$ in tetrahedral configuration and indicates a decrease in the lattice parameters without any change in the wurtzite structure as long as the cobalt $\mathrm{Co}^{2+}$ replaces $\mathrm{Zn}^{2+}$ ion in $\mathrm{ZnO}$ crystal lattice [24, 25].

Table 2 provides the positions and the width at mid-height (FWHM) of the peak (002) for different percentages of Co. In addition to the crystallite size calculated from Scherer's formula. The lowest FWHM value corresponds to the films with the lowest cobalt concentration (2\%), and as the number of cobalt increases, the FWHM of the peak (002) increases, indicating that the crystallinity of the films gradually deteriorates with the cobalt concentration.

Table 2. Peak position (002), FWHM, and crystallite sizes for different percentages of Co.

\begin{tabular}{c|c|c|c}
$\begin{array}{c}\text { Percentage of } \\
\text { Co }(\%)\end{array}$ & $\begin{array}{c}\text { Peak position } \\
(\mathbf{0 0 2})\left(\boldsymbol{(}^{\circ}\right)\end{array}$ & $\begin{array}{c}\text { Peak FWHM } \\
(\mathbf{0 0 2}) \boldsymbol{(}^{\circ}\end{array}$ & $\begin{array}{c}\text { Cristallite size } \\
(\mathbf{n m})\end{array}$ \\
\hline 0 & 34.45 & 0.18 & 53.0 \\
\hline 2 & 34.48 & 0.21 & 49.1 \\
\hline 5 & 34.51 & 0.25 & 39.5 \\
\hline 8 & 34.53 & 0.29 & 33.4
\end{tabular}

\subsection{Optical properties.}

The optical characterization of $\mathrm{ZnO}$ and $\mathrm{ZnO}-\mathrm{Co}$ thin films that we realized of a potential $\mathrm{E}=-1.0 \mathrm{~V} / \mathrm{SCE}$ for $30 \mathrm{~min}$ was realized by $\mathrm{UV}$-Visible spectroscopy.

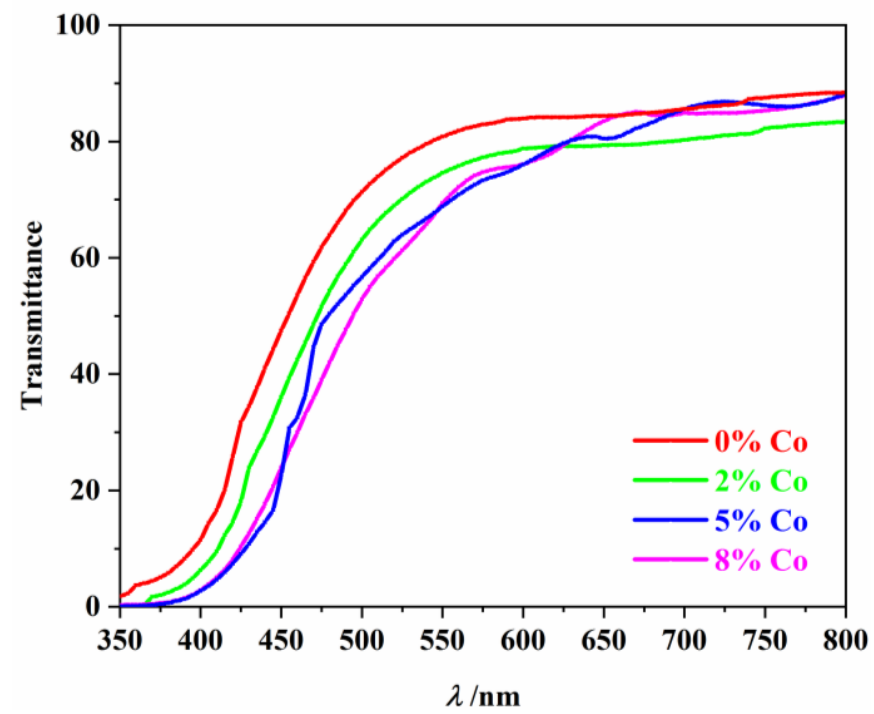

Figure 7. Transmission spectra of $\mathrm{ZnO}$ and Co-doped $\mathrm{ZnO}$ films deposited on ITO substrate by chronoamperometry. 
Figure 7 shows the normalized transmission in the wavelength range between 350-800 $\mathrm{nm}$ for $\mathrm{ZnO}$ and $\mathrm{ZnO}-\mathrm{Co}$ films elaborated at different percentages in Co. All samples show high transmission in the visible range.

In order to estimate the energy of the gap $\mathrm{Eg}$ of $\mathrm{ZnO}$ and Co-doped $\mathrm{ZnO}$ films, the characteristic curves $(\alpha h v)^{2}$ as a function of $h v$, according to Tauc equation(Eq.12), for $\mathrm{ZnO}$ and the $\mathrm{ZnO}-\mathrm{Co}$ with different doping rates, have been plotted in Figure 8.

$$
(\alpha h v)^{2}=\mathrm{B}(\mathrm{h} v-\mathrm{Eg})
$$

The curves clearly show an increase in gap energy from 3.36 to $3.51 \mathrm{eV}$ as the Co percentage increases from 2 to 8 . The blue shift of Eg has already been observed and explained as being due both to the sp-d exchange interactions between $\mathrm{ZnO}$ sp-band electrons and localized $\mathrm{Co}^{2+} \mathrm{d}$-band electrons and to the affectation of the $\mathrm{ZnO}$ band electron structure when the $\mathrm{Co}^{2+}$ ions move to the $\mathrm{Zn}^{2+}$ substitution position [26-34]. These figures show a large blue shift of the bandgap corresponding to the samples of undoped and $2 \%$ cobalt-doped $\mathrm{ZnO}$ nanorods. It is evident from the graphs that the direct bandgap increases by $2 \%-8 \%$ cobalt doping. This is consistent with the quantum confinement effects of nanoparticles.

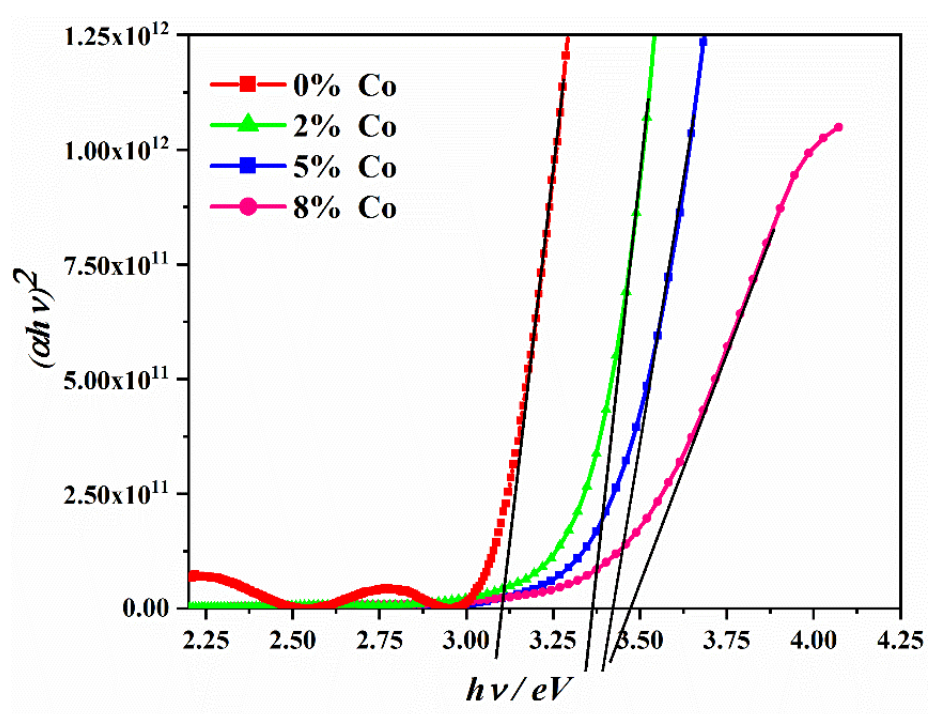

Figure 8. Plot of $(\alpha h v)^{2}$ versus (hv).
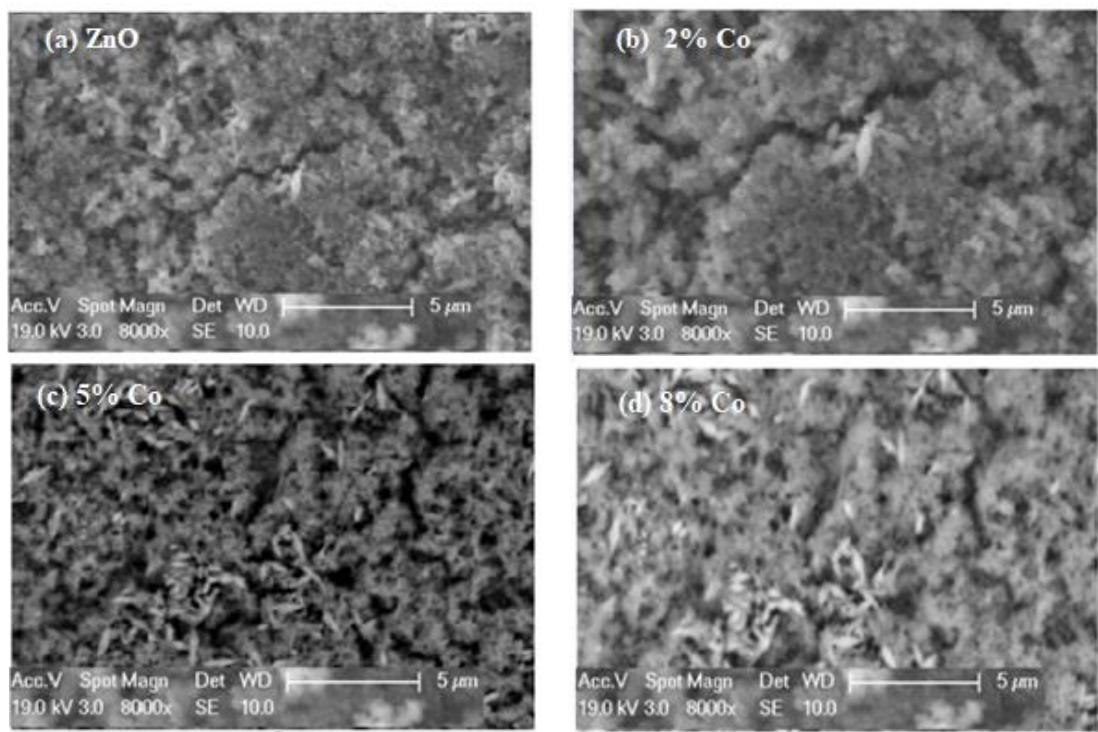

Figure 9. SEM image $\mathrm{ZnO}$ and $\mathrm{ZnO}$ doped Co electrodeposited on ITO substrate at potential -1.0 V/SCE. 
4.3. Scanning electronic microscope (SEM).

Figure 9 shows SEM image of $\mathrm{ZnO}$ and Co-doped $\mathrm{ZnO}$ electrodeposited on ITO substrate by establishing a potential of $\mathrm{E}=-1.0 \mathrm{~V} / \mathrm{SCE}$ during 30min. In Figure 9 (a, b, c and d), we notice that the deposit completely covers the surface of ITO substrate. Nanoparticles can be seen in $\mathrm{ZnO}$ and Co-doped $\mathrm{ZnO}$ samples, and the deposit presents in the form of homogeneous nanorods, which are densely oriented in different directions. The SEM analysis shows an increase in nanorods formation with an increase in cobalt doping percentage.

\section{Conclusions}

In the present study, $\mathrm{ZnO}$ doped $\mathrm{Co}$ thin films were deposited by the electrodeposition method on the ITO substrate. The electrochemical study of $\mathrm{ZnO}$ doped Co shows that whatever the percentage of $\mathrm{Co}$, the nucleation mechanism is always 3D instantaneous and under diffusion control as the microscopy scanning (MEB) allows us to confirm that. The diffractograms show that the co-deposition keeps the same Würtzite structure as $\mathrm{ZnO}$. The transmittance curves as a function of wavelength show that the co-deposit is transparent in the range and that the gap increases with the percentage of Co from $3.36 \mathrm{eV}$ for the percentage of cobalt from $2 \%$ to $3.51 \mathrm{eV}$ for the percentage of $8 \%$ cobalt.

\section{Funding}

This research received no external funding.

\section{Acknowledgment}

The authors would like to thank all laboratory members of bio-geosciences and materials engineering for their support and help. We also thank all the colleagues who assisted in performing the XRD analysis at the Faculty of Science Ain Choq Casablanca.

\section{Conflicts of Interest}

The authors declare no conflict of interest.

\section{References}

1. Lghazi, Y.; Moubah, R.; Bimaghra, I.; Hlil, E.K.; El Bahraoui, T.; Alleg, S. and Lassri, H. Investigation of Structural and Magnetic Properties in Electrodeposited Co/CoxZn1-x Superlattices. J. Supercond. Nov. Magn. 2017, 30, 2641-2645.

2. Jo, G.H.; Koh, J.H. Laser annealing effects on Ga dopants for $\mathrm{ZnO}$ thin films for transparent conducting oxide applications. Ceram. Int. 2019, 45, 6190-6197, https://doi.org/10.1016/j.ceramint.2018.12.096.

3. Siddheswaran, R.; Rostislav Medlín, C.; Esther Jeyanthi, S.; Gokul, Raj, R.; Mangalaraja, V. Structural, morphological, optical and magnetic properties of RF sputtered Co doped $\mathrm{ZnO}$ diluted magnetic semiconductor for spintronic applications. Appl. Phys. A 2019, 125, 1-9, https://doi.org/10.1007/s00339-0192886-0.

4. Yuvaraj, S.; Manikandan, N.; Vinitha, G. Effect of Zn2+ ions on third order nonlinear optical behavior and power limiting properties of manganese ferrite nanoparticles. Photonics Nanostruct. 2021, 45, 100922.

5. Thirupathi, C.; Nithiyanantham, S.; Sentilkumar, M.; Arivudainambi, A.; Mahalakshmi, S.; Natarajan, B. Synthesis and Characterization of Co-Doped ZnO Diluted Magnetic Semiconductor for Spintronics Application. Adv. Sci. Eng. Med. 2020, 12, 524-529, https://doi.org/10.1166/asem.2020.2554. 
6. Sharma, P.; Gupta, A.; Rao, K.V.; Owens, F.J.; Sharma, R.; Ahuja, R.; Guillen, J.O.; Johansson, B.; Gehring, G.A. Ferromagnetism above room temperature in bulk and transparent thin films of Mn-doped ZnO. Nat. Mater. 2003, 2, 673-677, https://doi.org/10.1038/nmat984.

7. Khan, R.; Althubeiti, K.; Afzal, A.M.; Rahman, N.; Fashu, S.; Zhang, W.; Khan, A.; Zheng, R. Structure and magnetic properties of $(\mathrm{Co}, \mathrm{Ce})$ co-doped $\mathrm{ZnO}$-based diluted magnetic semiconductor nanoparticles. $J$. Mater. Sci.: Mater. Electron. 2021, 1-7.

8. de Godoy, M.P.F.; Gratens, X.; Chitta, V.A.; Mesquita, A.; de Lima Jr, M.M.; Cantarero, A.; Rahman, G.; Morbec, J.M.; de Carvalho, H.B. Defect induced room temperature ferromagnetism in high quality Co-doped ZnO bulk samples. J. Alloys Compd. 2021, 859, 157772, https://doi.org/10.1016/j.jallcom.2020.157772.

9. Ait Ahmed, N.; Eyraud, M.; Hammache, H.; Vacandio, F.; Sam, S.; Gabouze, N.; Knauth, P.; Pelzer, K.; Djenizian, T. New insight into the mechanism of cathodic electrodeposition of zinc oxide thin films onto vitreous carbon. Electrochim. Acta 2013, 94, 238-244.

10. Ait Ahmed, N.; Hammache, H.; Eyraud, M.; Chassigneux, C.; Knauth, P.; Makhloufi, L.; Gabouze, N. Morphological and optical properties of $\mathrm{ZnO}$ thin films grown on Si and ITO glass substrates. Ionics 2018, 24, 277-284, https://doi.org/ff10.1007/s11581-017-2194-7.

11. Lakhdari, M.; Habelhames, F. Morphological and structural control of pulse electrodeposited $\mathrm{ZnO}$ thin films and its influence on the photoelectrocatalytic degradation of methyl orange. J. Mater. Sci. Mater. Electron. 2019, 30, 6107-6115.

12. Khajavi, M.R.; Blackwood, D.J.; Cabanero, G.; Tena-Zaera, R. New insight into growth mechanism of ZnO nanowires electrodeposited from nitrate-based solutions. Electrochim. Acta 2012, 69, 181-189, https://doi.org/10.1016/j.electacta.2012.02.096.

13. Kamysheva, K.A.; Shekhanov, R.F.; Gridchin, S.N.; Balmasov, A.V. Electroplating of zinc and tin alloys with nickel and cobalt from ammonium oxalate electrolytes. Russ. Chem. Bull. 2020, 69, 1272-1278, https://doi.org/10.1007/s11172-020-2897-1.

14. Villarreal, C.C.; Pirzada, D.; Wong, A.; Mulchandani, A. Electrodeposition of ZnO nanorods on graphene: tuning the topography for application as tin oxide-free electron transport layer. J. Appl. Electrochem. 2021, $1-13$.

15. Lghazi, Y.; Bimaghra, I.; Bachiri, A.; Elmerzouki, K.; Youbi, B.; Lasri, H. Investigation of the Nucleation Kinetics of $\mathrm{Bi}$ and $\Delta-\mathrm{Bi}_{2} \mathrm{O}_{3}$ During Electro-Deposition on Substrate ITO. Int. J. Eng. Technol. 2018, 7, 2124, https://doi.org/10.14419/ijet.v7i4.32.23238.

16. Abid, M.; Abid, J.P.; Ansermet, J.P. Ferromagnetism at Room Temperature on Electrodeposited Co Doped ZnO Thin Film. J. Electrochem. Soc. 2006, 153, D138.

17. Scharifker, B.; Hills Theoretical and experimental studies of multiple nucleation. Electrochim. Acta 1983, 28, 879-889, https://doi.org/10.1016/0013-4686(83)85163-9.

18. Youbi, B.; Lghazi, Y.; Ait Himi, M.; Bimaghra, I. Nucleation and growth mechanism of tellurium electrodeposited on tin-doped indium oxide substrate. J. Appl. Electrochem. 2020, 50, 159-168, https://doi.org/10.1007/s10800-019-01377-0.

19. Ait Himi, M.; Youbi, B.; Lghazi, Y.; Bimaghra, I. Nucleation and growth mechanism of manganese oxide electrodeposited on ITO substrate. Mater. Today: Proc. 2020, 30, 963-969.

21. Hernandez, T.S.; Barile, C.J.; Strand, M.T.; Dayrit, T.E.; Slotcavage, D.J.; McGehee, M.D. Bistable Black Electrochromic Windows Based on the Reversible Metal Electrodeposition of $\mathrm{Bi}$ and $\mathrm{Cu}$. ACS Energy Lett. 2018, 3, 104-111, https://doi.org/10.1021/acsenergylett.7b01072.

22. Bahar, J.; Lghazi, Y.;Youbi, B.; Himi, M.A.; Bimaghra, I. Comparative study of the nucleation and the growth mechanism of cobalt electrodeposited on an ITO substrate in nitrate and chloride electrolytes. J. Solide State Electrochem. 2021, 25, 1889-1900, https://doi.org/10.1007/s10008-021-04961-7.

23. Gunawardena, G.; Hills, G.; Scharifker, B. Induction times for the formation of single mercury nuclei on a platinum microelectrode. J. Electroanal. Chem. 1981, 130, 99-112.

24. Youbi, B.; Lghazi, Y.; Himi, M.A.; Bahar, J.; Bimaghra, I. Growth mechanism during the early stages of electrodeposition of bismuth telluride Bi2Te3 on ITO substrate. Mater. Today: Proc. 2019, 30, 842-848, https://doi.org/10.1016/j.electacta.2015.05.190.

25. Tortosa, M.; Mollar, M.; Marí, B.; Lloret, F. Optical and magnetic properties of ZnCoO thin films synthesized by electrodeposition. J. Appl. Phys. 2008, 104, 1-6.

26. Guermat, N.; Daranfed, W.; Bouchama, I.; Bouarissa, N. Investigation of structural, morphological, optical and electrical properties of $\mathrm{Co} / \mathrm{Ni}$ co-doped $\mathrm{ZnO}$ thin films. J. Mol. Struct. 2021, 1225, 129134, https://doi.org/10.1016/j.molstruc.2020.129134. 


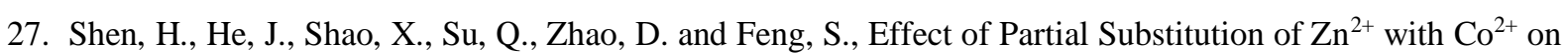
Catalytic Methane Combustion Performance of $\mathrm{Zn} 1-\mathrm{xCoxGa} 2 \mathrm{O} 4(\mathrm{x}=0,0.1,0.3)$ Microspheres. Solid State Sci. 2021, 106678.

28. Peng, Y.Z.; Liew, T.; Song, W.D.; An, C.W.; Teo, K.L.; Chong, T.C. Structural and optical properties of Co-doped ZnO thin films. J. Supercond. Nov. Magn. 2005, 18, 97-103, https://doi.org/10.1007/s10948-0052158-4.

29. Duan, Y.; Ma, J.; Dai, J.; Qiang, L.; Xue, J. Morphology engineering of ZnO nanostructures for enhanced photocatalytic efficiency of In (OH) 3/ZnO nanocomposite. Appl. Surf. Sci. 2021, 535, p.147657.

30. Samoshkina, Y.E.; Edelman, I.S.; Chou, H.; Lin, H.C.; Dwivedi, G.D.; Petrov, D.A.; Zharkov, S.M.; Zeer, G.M.; Molokeev, M.S. Structure and physical properties of hydrogenated $\left(\mathrm{Co}^{+} \mathrm{Al}\right)$-doped $\mathrm{ZnO}$ films: Comparative study with co-doped ZnO films. Mater. Sci. Eng., B 2021, 264, p.114943.

31. Batista, E.A.; Silva, A.C.A.; de Lima, T.K.; Guimarães, E.V.; da Silva, R.S.; Dantas, N.O. Effect of the location of $\mathrm{Mn}^{2+}$ ions in the optical and magnetic properties of $\mathrm{ZnO}$ nanocrystals. J. Alloys Compd. 2021, $850,156611$.

32. Fan, Y.; Xu, Y.; Wang, Y.; Sun, Y. Fabrication and characterization of Co-doped ZnO nanodiscs for selective TEA sensor applications with high response, high selectivity and ppb-level detection limit. J. Alloys Compd. 2021, 876, 160170.

33. Mukhopadhyay, O.; Dhole, S.; Mandal, B.K.; Khan, F.R.N.; Ling, Y.C. Synthesis, characterization and photocatalytic activity of $\mathrm{Zn}^{2+}, \mathrm{Mn}^{2+}$ and $\mathrm{Co}^{2+}$ doped $\mathrm{SnO}_{2}$ nanoparticles. Biointerface Res. Appl. Chem. 2019, 9, 4199-4204, https://doi.org/10.33263/BRIAC95.199204.

34. Droepenu, E.K.; Wee, B.S.; Chin, S.F.; Kok, K.Y.; Asare, E.A. Synthesis and characterization of single phase $\mathrm{ZnO}$ nanostructures via solvothermal method: Influence of alkaline source. Biointerface Res. Appl. Chem. 2020, 3, 5648-5655, https://doi.org/10.33263/BRIAC103.6486550. 